\title{
On "Meaning and Experience"
}

\section{Olav Gjelsvik *}

\section{Introduction}

Dagfinn Føllesdal's wonderful paper "Meaning and Experience" pursues a general position on meaning, and it does so from a Husserlian background while responding both to Quine's and to Davidson's philosophical work on the topic. The present paper aims to assess the philosophical significance of this contribution. It is natural for me to engage with Føllesdal's position by looking at the ways it interacts and also contrasts with Quine or Davidson. I shall mainly look at the last interaction, but also a little bit at the first. The structure of this paper is as follows: I shall first introduce the problems that I shall pursue, and place Føllesdal's points and contributions in a philosophical context. I will then supply some of my own thoughts on the same cluster of problems, and on this background evaluate his contribution. ${ }^{1}$

\section{Føllesdal's main critical point against Davidson's view on radical in- terpretation}

Let me start directly with the main critical point Føllesdal makes about Davidson in 1975. According to Føllesdal 1999 he first made the point to Davidson when they were walking together in the hills in the neighbourhood of Biel in 1973. At the time Davidson's main instruction for radical interpretation was "Maximize Agreement". This rule needs tempering

\footnotetext{
${ }^{*}$ CSMN, Universitetet i Oslo

${ }^{1}$ I develop my thoughts about Davidson's main project on meaning and radical interpretation in my "Knowledge and error: a new approach to radical interpretation", in Donald Davidson on Truth, Meaning and the Mental, ed. G. Preyer, Oxford, OUP, 2012, pp.167-191. That paper contains some of the same discussions of Davidson as this chapter, but takes things much further and places them in a general systematic context.
} 
with, Føllesdal argues. Imagine that a big tree is between the speaker and the only rabbit present, and that the interpreter sees this. In that case one should not expect agreement between speaker and interpreter about whether a rabbit is present. One should therefore not maximise agreement at all costs, one should limit agreement somewhat; at least to the cases where disagreement is not to be expected. What is present or absent to the senses of the speaker and the interpreter respectively plays an important role in the identification of the cases where disagreement is to be expected. Note that if one were engaged in radical interpretation, entertained the hypothesis that "gavagai" meant rabbit, and really maximized agreement in this situation, one would most likely throw away a correct translation/interpretation hypothesis.

Davidson immediately responded to Føllesdal that radical interpretation should be based on weighted agreement. Føllesdal found this promising, but also pointed out that such a theory "does not relieve the translator and student of meaning from considering what is happening at our sensory surfaces. On the contrary, a main source of evidence for a rational person is his sensory evidence. For this reason, a special premium must be put on agreement between similarly placed observers. And this notion of similarly placed observers brings us directly back to the problem of intersubjective comparisons of stimulations we discussed with Quine."2

Looking at the discussions of Quine in the same paper, i.e. the discussions Føllesdal refers to in the quote above, we see that Føllesdal agrees with Quine about the importance of sensory evidence, but disagrees with Quine on what sensory evidence is. Føllesdal's main charge against Quine on the latter point is that Quine's identification of stimulations with triggerings of nerve endings sets us off on the wrong track. It does not preserve Quine's own insight that meaning in language is a social phenomenon. Føllesdal suggests that we instead of going inside the skin should "identify stimulations with the pattern of chromatic irradiation, sound vibration, etc., just outside, or at the sensory surfaces.",3

Føllesdal sums his position up by saying that a theory of meaning should include at least two things; both the structure of a truth-theory and a

\footnotetext{
${ }^{2}$ Føllesdal (1975), p. 40.

${ }^{3}$ Føllesdal (1975), p. 35.
} 
condition concerning weighted agreement, in which what is going on at our sensory surfaces plays an important role. In addition he points to many other things that plays a role.

Now, I think we should all agree that what is going on at the sensory surfaces in this sense plays an important role that a theory of meaning should recognize one way or other. But I also see a need to say quite a bit more about what exactly this role is or should be in an account of meaning and content. It looks to me as Føllesdal here in 1975 might be siding with Quine against Davidson on the issue of proximal versus distal stimuli or input, as this question has been pursued in the later debates between Davidson and Quine. My own view is that we should in a way not side with any of them, and that this is important. I hope Føllesdal is with me in this, and also with me when I pursue what role, exactly, we should give to sensory evidence.

\section{Davidson's response to Føllesdal}

Let me now turn to Davidson's later thoughts about error and input. Here is Davidson about error in his Dewey-lectures, "The Structure and Content of Truth". He is here commenting on the difficulties for his own distal (as opposed to Quine's proximal) input theory when explaining error. The distal inputs are out there in the environment of the speaker:

The difficulty with the distal theory is that it makes error hard to explain, the crucial gap between what is believed true and what is true. ... The solution depends on two closely related interpretative devices. An interpreter bent on working out a speaker's meanings notes more than what causes assents and dissents, he notes how well placed and equipped the speaker is to observe aspects of his environment, and accordingly gives more weight to some verbal responses than to others. This provides him with the rudiments of an explanation of deviant cases where the speaker calls a sheep a goat because he is mistaken about the animal rather than the word. ${ }^{4}$

Note how Davidson's formulation in 1990 is quite close to Føllesdal's position in 1975. More than assent and dissent is needed, Davidson says; one also has to look at how well placed the speaker is for observation. This is

\footnotetext{
${ }^{4}$ See Davidson (1990), p.321.
} 
the basis for the weighting. What Davidson says tallies closely with Føllesdal's wording that "a special premium must be put on agreement between similarly placed observers". If there is a difference between Føllesdal and Davidson in 1990, it relates to the role of causality, and whether we can get at what objects we speak about and refer to by identifying causal interactions between the speaker and the environment. This further relates to the ambitions in Davidson's project of 1990. This project seems quite ambitious in that he says he aims to bridge the gap between the propositional and the non-propositional by starting with preferences for the truth of uninterpreted sentences in a physical environment where the radical interpreter observes causal interactions. It seems to me that Føllesdal is very clear that ambitions towards bridging this gap are misplaced. Føllesdal is furthermore very clear that just speaking of weighting will not do, one needs to say things directly about the role of evidence when explaining the principles of the weighting.

I shall now turn to another side of this, and that is what remains of the issue about distal or proximal input. In this context I find Davidson's notion of being well placed and equipped for observation interesting. It seems to me, however, that the notion we need in radical interpretation is not "being well placed and equipped for observation". What we need is the notion of being well placed and equipped for knowing by observation, or so I shall argue below. I shall indeed argue that this change does the trick in sorting out what is going on in the discussions about distal or proximal input. I shall first explore the issue of explicating and explaining error by looking at the case Davidson suggests in the long quotation from him.

The case is the case of sheep and goat, where the speaker is mistaken about the animal and not about the word. Mistakes can be of very many types. The case of the rabbit behind the tree exemplifies one type of case, where one is mistaken about whether an animal is there at all. If the present case is a case where the sheep has been dressed up as a goat, and it is almost impossible to spot the real nature of the animal just by looking, then it is a case where on is expected to be mistaken about the type of animal. Assumption now: The case of sheep and goat is of this sort. Note then that the speaker in this case, as opposed to the rabbit case, is in a plain sense very well placed and equipped for observing this animal since the animal is plainly in sight and the speaker's sight is good. The striking feature is that 
it is not easy at all to know by observation what animal it is. In fact it is a case where the speaker, in case the speaker possesses the concepts of sheep and goat, is strongly expected to believe that the animal is a goat. We can perhaps think of this case as case where we cannot explain that the speaker $\mathrm{S}$ does not make the relevant error about the world. ${ }^{5}$ By Føllesdal's terminology from 1975, we can say that it is a case where the surface stimulations are identical. Same surface stimulations, same beliefs and same words.

Davidson's phrase is, however, "how well placed and equipped the speaker is to observe aspects of his environment". My question here is whether this phrase captures what he needs to capture. Davidson's explanation of error should according to this phrase, I presume, work by explaining error by pointing out that the speaker is not well placed or equipped to observe in the erratic case. Note that in the case of the rabbit behind the tree, introduced by Føllesdal in 1973, we can explain the error quite well by employing Davidson's phrase. Perhaps the phrase has been coined in response to that example. If, however, we were to explain the false belief in the present case of the sheep and goat by employing that same phrase of Davidson's, then it will not work so easily. This is because the speaker in a plain sense is well placed to observe. There is no problem in observing the animal. The intuitive difficulty in this case is that the speaker who is well placed to observe is not well placed or equipped to

\footnotetext{
${ }^{5}$ When things are like this, they will have specific implications for interpretation of his words if the speaker insists on calling this sheep a sheep even when he ought to call it a goat according to our tentative interpretation. A different - weaker and intermediate - case is the case where it is understandable and explainable that the speaker mistakes the sheep for a goat, but many speakers, also this one, does not always make a mistake here. Then the case will have less obvious implications for the interpretation of words if the speaker according to out tentative interpretation says that the animal in front is a sheep. There will be a variety of such cases, and the interpreter will work towards some trade-off in interpretation, look at many different cases etc. The point I will stress is only that if we epistemically expect error, and there is no reasonable explanation of why the error is not made, as in the case above with the dressed up sheep, not distinguishable from a goat, and there is no slip of the tongue or any other slip that gets corrected by further questioning, then we do have a case which has very obvious implications for attributions of meaning.

${ }^{6}$ My italics.
} 
know by observation what sort of animal it is. We therefore have a prima facie case for replacing Davidson's phrase with the phrase "being well placed or equipped to know by observation". If that is what we need to explicate error in cases of this sort, then there is a need to employ the concept of knowledge in explicating error. These matters deserve, however, a much closer look. $^{7}$

\section{Preparing to explicate error: Simple and not so simple attributions}

Of primary interest when doing radical interpretation are statements about what the speaker S sees, hears, smells, etc. Such statements provide an essential part of the story of what causes assent and dissent. I shall call such attributions simple attributions. We can think of the case where a simple attribution is true as a case where the subject is provided with evidence in the matter at hand.

One first point is now this: An explanation of false beliefs works by attributing to $\mathrm{S}$ not only evidence in this sense of evidence, but also by attributing epistemic sensitivity to such evidence, or to the reasons for belief the evidence provides. We typically explain error by pointing to how things looked or appeared to S, rather than plainly pointing to what S saw. When we point to the latter we do that in a way that precisely indicates or exhibits how things must have looked to the speaker. A man believes falsely that he saw a bear, because he saw a man dressed up like bear. We might just say that he saw a man that looked exactly like a bear and leave it at that. Then we assume that $\mathrm{S}$ was sensitive towards this evidence (things

\footnotetext{
${ }^{7}$ The notion of triangulation plays an important part in late Davidson. To me it is somewhat unclear what use Davidson makes of it. It can be taken as a further specification of his traditional radical interpretation set-up, as further details about how to move from attribution of preferences between uninterpreted sentences in situations to an attribution of a full semantical theory and corresponding beliefs. In that case it is just more about what I do in my text, in particular it provides details about how to get to the simple perceptual attributions I describe. It can also be taken as a more ambitious philosophical theory that is meant to go some way towards accounting for what intentional contents are, or towards how intentional content is possible at all, i.e. it might move towards a full-blooded theory of meaning in M. Dummett's sense of the latter. This latter project is not my project. It is not even a project I am in a position to recommend.
} 
looking like bears) and formed the corresponding (false) belief that there was indeed a bear.

In the normal case a sheep looks like a sheep. Still, how things appear to $\mathrm{S}$ may not be captured by a simple description of what $\mathrm{S}$ sees. When these things come apart, then the state described by the former type of description is typically, but not exclusively, caused by what $\mathrm{S}$ sees, hears, smells, etc. We have in fact general knowledge of such causal patterns, and we have no empirical grip of ascribing how things look and appear to $\mathrm{S}$ in isolation from ascriptions of what $\mathrm{S}$ sees, hears, etc. This general type of knowledge of such connections must in interpretation be applied by us, and obviously this general knowledge can only be applied in the light of what $\mathrm{S}$ sees, hears etc. It is therefore a fact that we need attributions with the notions "S sees...", (example: S sees a sheep), "S hears....", and others on our way towards interpretative hypotheses.

The simple attributions a radical interpreter makes, the attributions of what the speaker sees and hears, have two fundamental properties that make them very appealing to a radical interpreter. Firstly, they are attributions which can be made by the interpreter without any implications about what concepts the speaker possesses, or any assumptions about the finegrained propositional attitudes of the speaker. Secondly, if you see a sheep eating grass, we can validly infer that there is a sheep eating grass that you see. Simple attributions are factive and imply truth in this sense: The simple attribution cannot be true unless the thing that you see or hear is there, with the properties ascribed to it in the noun phrase of the simple attribution.

Look then at this complex attribution, and think of that as typical: "It appears to the speaker that there is a sheep there." The semantics of this attribution is entirely different from the simple attributions in the paragraph above. In this case, if the attributions are correct, the speaker must necessarily master all the concepts in use after the "that". Secondly, such attributions do not imply that the content, that a sheep is eating grass, is a true one. In some cases we attribute this content knowing perfectly well that the purported sheep is a goat dressed up like a sheep. These attributions are clearly fully loaded with intentionality, even intentionality in the Husserlian sense. Let us proceed towards explication of error. 


\section{Explications of error}

Take again the case where there is a sheep dressed up exactly as a goat. What is needed then in order to explain the error is to make use of the fact, if is a fact, that it "appears to S that he is seeing a goat". We attribute epistemic sensitivities toward seeing a dressed up sheep looking like a goat ("It looked to S exactly as a goat"), and on that basis we attribute the false belief to $\mathrm{S}$ that "There is a goat". The role of "S sees a sheep" is fundamental in this explanatory enterprise, (and it accounts for the falsehood), but equally fundamental is the attribution of the evidential sensitivities to the speaker towards the fact that the animal in question looks like a goat. We have to bring in all of these things to attribute the false belief in the radical interpretation framework, for then to make use of that attribution of false belief in making adjustments in interpreting words on the basis of the preference for the truth of sentences.

It is agreed that we in an interpretative hypothesis typically tentatively attribute very many concepts and a host of true beliefs to the speaker. I claim we must in a similar fashion make all the simple attributions, and on that basis attribute epistemic sensitivities related to the concepts we also attribute, albeit tentatively. When we attribute the epistemic sensitivities in these cases ("It looked to S exactly as a goat"), we do, I claim, tentatively attribute some knowledge to S, namely knowledge about goats; what they are, and how they look and appear. Without such knowledge, the epistemic sensitivities that underlie the attributions of false beliefs seem to be missing.

To sum up: The explication of error works by two types of attributions, the simple attributions of "seeing a sheep dressed up like a goat", in conjunction with the complex attribution of evidential sensitivities which involve "knowing how a goat looks". Davidson thought, erroneously, that you could explain error by the phrase "being well placed or equipped to observe". But in our case of error it is not as if error is to be ruled out as long as this predicate applies. Only if we read the phrase in question as "being well placed or equipped to know by observation", do we really get on our way towards capturing what we need for the explication of this type of error. If this is right, it follows directly that error in these central cases amounts to failed knowledge. The notion of failed knowledge must then be 
understood against the background where we normally do know by observation.

\section{Pulling together in a larger picture}

It seems really obvious by now that we need more than simple attributions to explicate error; we need to ascribe a conceptual repertoire and evidential sensitivities to the speaker. In order to account for error, we therefore need to move past the stage I like to identify as the initial stage of radical interpretation. This initial stage limits itself to verbal behaviour in situations in which the speaker is very well placed and equipped to know by observation the relevant aspects of his environment. The contents in question are such that we hold that were they to be entertained, the speaker would know them to be true. This first stage of radical interpretation concentrates on the cases where there is no reason to expect a mismatch in content between what is the case, simple attributions, and tentative complex attributions about how things appear. These are the cases where we see sheep and goats plainly in view, sheep and goats that look like sheep and goats. From this starting point we can move towards tentatively interpreting an interesting, albeit limited, part of the speaker's language. It also gives us resources for being able to start to account (still tentatively, though) for this type of error. Attributions of error can be conceived of as occurring on a second stage where we go beyond such simple situations, and adjust our interpretative hypotheses in the new terrain. The attribution of error takes place against the background of the attributions of knowledge, the knowledge that is crucial to explicate error.

This procedure gives first priority to the verbal behaviour in the cases where we with reason can be said to know by observation. By employing the concept of knowledge by observation we identify these cases where there is indeed a match between the distal and proximal input, the initial phase of interpretation. We move so to speak beyond the defining battle ground, Quine and Davidson's battle ground over whether we should go for distal or proximal stimuli, by first employing a concept which holds these two other concepts, the proximal and the distal, together in the right way. This is what the concept of knowledge here does. My argument is therefore meant to show the need for a concept of this exact nature, and for starting radical interpretation with cases identified by employing this con- 
cept. When we move beyond these simple cases where knowledge by observation is easy and natural, then we also have the resources to give the right weight to how things look to the speaker, and we are able to identify explicable errors.

We can sum this up by saying that we ought to make tentative attributions of types of knowledge to get well started in radical interpretation, and we also need to be able to attribute types of knowledge in order to be able to make attributions of false belief rather than adjusting our interpretative hypothesis in the more complex cases. There is a clear sense in which many errors can be seen as failed knowledge.

\section{Is the introduction of the concept of knowledge necessary?}

Most people find it incredible that we should employ the concept of knowledge at the very basic level in radical interpretation. This is very hard to digest if one thinks of knowledge as justified true belief. And I openly state that my aim here is a larger one of giving knowledge its rightful role in an account of content. Some people commenting in my view have said that Davidson should instead speak of "being well placed and equipped to acquire true belief by observation."

This latter move by Davidson would be very welcome to me. However, Gettier cases shows us that we are unable to provide reductive definitions of knowledge, and they also illustrate that true beliefs acquired by observation is a problematic notion. If the case at hand, facing the radical interpreter, is a Gettier case, should it be taken as belonging to this first stage of radical interpretation? I think not, but will not argue the case in detail. Note that the amendment to Davidson's view seems to have to let the Gettier case in among the simple cases, and that is deeply problematic.

Let me instead turn to the attribution of knowledge of how things look in the explanation of error, and our example. Perhaps we should not attribute knowledge here, but just beliefs about how goats appear. Not just any beliefs, of course, these beliefs would also have to be mainly true. If not, the explanation of error would not work. That explanation assumes that the sensitivity to the evidence is really there. For that to be so, we can hardly allow any central false beliefs about how goats look and appear, for instance the belief that goats are only turquoise in colour. True beliefs about how the animals appear need not be constitutive of having the con- 
cept of a goat; that is true. The concept of goat must, however, be correctly attributed for the explanation of error to work, and so must the epistemic sensitivity towards the animal which in this case looks like a goat. For the latter, the sensitivity, we need to attribute many true beliefs about how goats look. Is Davidson's position that we should at this point only attribute many true beliefs, and no knowledge, about how goats look to the speaker? I must admit that I cannot see clearly how Davidson's view in that case would be motivated. We have, I stress, no general reason against attributing knowledge. Refraining from attributing knowledge of how goats look in the case of someone with the concept of goat is normally something we do just in case there is a specific reason for not attributing knowledge about how goats look. That is not so in our case. In fact, we normally think of the fact that a person does know how goats look as what accounts for the fact that the person has a large number of true beliefs about how they look.

Knowing how goats look is therefore naturally taken as what underlies having the right sort of evidential sensitivity when you are well placed and equipped to see or hear a goat; the sort of evidential sensitivity which in its turn underlies the fact that you will be expected to believe falsely that you see a goat when presented with a sheep dressed up to look almost exactly like a goat. Knowing how a goat looks means being familiar with the way goats look, and presupposes having the concept of a goat. The person who is attributed the knowledge about how they look, is typically attributed the concept of a goat on the basis of discriminative behaviour and epistemic sensitivity towards them, and that is in radical interpretation attributed partly on the basis of attitudes towards utterances of sentences in simple situations. The simple situations are naturally identified as the situations where we can easily know by observation, and we can be attributed knowledge of the truth of the content if attributed entertainment of the content in question.

\section{Føllesdal's contribution seen from my point of view}

Føllesdal stressed in 1975 the importance for interpretation of what is going on at the sensory surfaces. In stressing this, his position was a great improvement on both Quine and Davidson at the time. We can now see that the sensory surfaces are very important indeed. But we should also in- 
vestigate the way they are important. Føllesdal also stressed that perception has propositional content, and as he says, that it can "thereby serve as evidence for judgment". ${ }^{8}$ How do these two things hang together?

I agree fully with Føllesdal that having propositional content is necessary for serving as evidence. But this feature in itself is not sufficient for identifying the perceptual states that are to count as evidence in the beginning phases of radical interpretation when we get the first tentative interpretative hypothesis reasonably well established. This seems to be the morale of the example with a sheep dressed up as a goat.

We are engaged in the project of giving perceptual evidence a significant role in an account of meaning and content, and in this sense we have learned from Quine. My suggestion is that we do that step-wise. There are elements of that two-step thinking also in Quine and Davidson, in particular in Quine, with his stress on observation and occasion sentences and the special roles for such data. In fact, my approach would perhaps start from many of the same situations as the one's Quine would start from, even if the conception of the initial phase is very different. The discussion above seems to support this thought: Evidence in the required sense is simply what we would know by looking if we had the concepts involved in the attribution. In this case this can be generalized to the unproblematic perceptual knowledge we have in the cases when we can take as evidence what we see, hear, smell and feel. I agree that some times the evidence is how things look and appear only. I agree that some times it is easier to know how things look than to know what they are. But these cases are complex cases, and we should get to them later in the game. The states we should start with are the states we think of as providing perceptual knowledge. These states are factive states, as are also, in my view, the state of experiencing something happen and the state of observing something happen. Knowledge is the most general factive state, and all these other states are instances of knowledge. Among these various factive states the ones captured by the simple attributions stand out by the fact that they do not imply much about the speaker's sensitivity towards the evidence provided. That is why someone engaged in radical interpretation should be so keen on them. A lot more is implied in cases like attributions of experience or ob-

\footnotetext{
${ }^{8}$ Føllesdal (1999), p. 725.
} 
servation, and that ties in with the fact that the latter attributions imply many things about one's conceptual repertoire.

What is going on at the sensory surfaces of a person is not normally evidence that this person has. It is not even conceptually structured. But knowledge about what is going on at the sensory surfaces is of vital importance for the radical interpreter when making simple attributions in order to get rudimentary interpretation going, and for giving explicable error the right role when interpretation develops further. It is a central part of the causal knowledge we need in order to make simple attributions, and thus in order to start to explicate error. But its role and status is a causal one, and in order to see its relevance we cannot just look at such causal facts alone, we need to see their relevance as a vital part of the picture when identifying what we are well placed to know by observation. What matters is the attribution of what we see and hear, and of how things look and sound. The work of causality and the causal facts we assume are always structured by the conceptual structure we tentatively attribute to the speaker. It is also this same conceptual structure that provides structure to what we hypothesize the speaker can know by observation. Our causal knowledge is then vital for determining in particular cases whether the speaker's states are in fact of this or that observational sort. Our causal knowledge is essential for attributing, tentatively, knowledge to the speaker of the world around her/him. On the present approach, attributions of meaning should be seen against the backdrop of such simple knowledge attributions. That brings out the role of evidence in the account of meaning.

In saying this, I have moved much beyond Dagfinn's actual formulations, and I have in my particular way, by employing knowledge, stressed the distal more than he did in 1975, and perhaps more than he still does. I do not expect him to agree with me in all I have said. But I think I have pointed to a way that takes us beyond the opposition between proximal and distal. Looking back at the debate between Quine, Davidson and Føllesdal from my perspective, we can see that Føllesdal is the one who first formulated the direction where the debate ought to go about meaning and content. He built on both Quine and Davidson, and he built more on Quine 
than on Davidson. What made him able to point to the direction forward, Føllesdal might say, was the way he had studied Husserl. ${ }^{9}$

\section{References}

Davidson, Donald (1990) "The Structure and Content of Truth", Journal of Philosophy, Vol. 87, 1990, pp. 279-328.

Davidson, Donald (1999) "Reply to Føllesdal", in The Philosophy of Donald Davidson, The Library of Living Philosophers, edited by L.E. Hahn, Chicago and La Salle, Open Court, 1999, pp. 729-732.

Føllesdal, Dagfinn (1975) "Meaning and Experience", in Samuel Guttenplan (ed.) Mind and Language, Oxford, Clarendon Press, 1975, pp. 25-44.

Føllesdal, Dagfinn (1999) “Triangulation”, in The Philosophy of Donald Davidson, The Library of Living Philosophers, edited by L.E. Hahn, Chicago and La Salle, Open Court, 1999, pp. 719-728.

Gjelsvik, Olav (2012) "Knowledge and error: a new approach to radical interpretation", in Donald Davidson on Truth, Meaning and the Mental, ed. G. Preyer, Oxford, OUP, 2012, pp.167-191.

Preyer, Gerhard, ed. (2012) Donald Davidson on Truth, Meaning and the Mental, Oxford, OUP, 2012.

Quine, W.V. (1960) Word and Object, Cambridge, Mass., MIT-Press, 1960.

${ }^{9}$ I thank Pascal Engel, Dagfinn Føllesdal, Peter Pagin, Bjørn Ramberg and Tim Williamson for helpful comments on this material. 